\title{
Práticas de leitura e escrita de mulheres camponesas: reflexões a partir de algumas histórias de apropriação
}

\author{
Sônia Maria Alves de Oliveira Reis ${ }^{1}$, Carmem Lúcia Eiterer ${ }^{2}$ \\ ${ }^{1}$ Universidade do Estado da Bahia - UNEB. Departamento de Educação. Avenida Universitária Vanessa Cardoso e Cardoso de \\ Lira, S/N. Ipanema. Guanambi - BA. Brasil. ${ }^{2}$ Universidade Federal de Minas Gerais - UFMG. \\ Autor para correspondência/Author for correspondence: sonia_uneb@hotmail.com
}

\begin{abstract}
RESUMO. Este texto objetiva apresentar práticas de leitura e escrita de mulheres camponesas com pouca escolarização. $\mathrm{O}$ estudo insere-se no quadro de pesquisas sobre os modos de participação nas práticas culturais relacionadas à leitura e à escrita por meio de distintas instâncias de socialização. Ele surgiu do pressuposto de que não existe uma cultura escrita já dada, mas sim uma diversidade de culturas do escrito que variam em função do contexto de uso e aprendizagem e não são exclusivamente dependentes da língua escrita baseada no sistema alfabético. A metodologia de investigação seguiu uma orientação dos pressupostos qualitativos de pesquisa. Utilizou-se história oral, diário de campo constituído a partir dos eventos de letramento observados nas CEBs e entrevistas, com a finalidade de identificar formas de acesso e apropriação de materiais escritos. Além disso, apresentam-se os significados, os papéis e as concepções que as líderes das CEBs atribuem à leitura e à escrita, especificamente a partir de algumas histórias de apropriação. Por intermédio dos procedimentos adotados na análise dos dados, foi possível interpretar que as diferentes formas de participação nas culturas do escrito dessas mulheres se pautam na mediação entre o oral e o escrito.
\end{abstract}

Palavras-chave: Mulheres Camponesas, Culturas do Escrito, Letramento, CEBs, Participação Cidadã. 


\title{
Reading and writing practices of peasant women: reflections from some appropriation stories
}

\begin{abstract}
This text aims to present practices of reading and writing of peasant women with little schooling. The study is part of the research on the ways of participating in cultural practices related to reading and writing through different instances of socialization. It arose from the assumption that there is no written culture yet, but rather a diversity of writing cultures that vary according to the context of use and learning that are not exclusively dependent on written language based on the alphabetic system. The research methodology followed an orientation of the qualitative research presuppositions. We used oral history, a field diary made up of the literacy events observed in the CEBs and interviews, in order to identify forms of access and appropriation of written materials. In addition, the meanings, roles, and conceptions that CEB leaders attribute to reading and writing are presented, specifically from some appropriation histories. Through the procedures adopted in the analysis of the data it was possible to interpret that the different forms of participation in the writing cultures of these women are based on the mediation between the oral and the written.
\end{abstract}

Keywords: Peasant Women, Writing Cultures, Literacy, CEBs, Citizen Participation. 


\title{
Prácticas de lectura y escrita de mujeres campesinas: reflexiones a partir de algunas historias de apropiación
}

\begin{abstract}
RESUMEN. Este texto objetiva presentar prácticas de lectura y escritura de mujeres campesinas con poca escolarización. El estudio se inserta en el marco de investigaciones acerca de los modos de participación en las prácticas culturales relacionadas a la lectura ya la escritura por medio de distintas instancias de socialización. El surgió del supuesto de que no existe una cultura escrita ya dada, sino una diversidad de culturas del escrito que varían en función del contexto de uso y aprendizaje que no son exclusivamente dependientes de la lengua escrita basada en el sistema alfabético. La metodología de investigación siguió una orientación de los presupuestos cualitativos de investigación. Se utilizó historia oral, diario de campo constituido a partir de los eventos de letramento observados en las CEBs y entrevistas, con la finalidad de identificar formas de acceso y apropiación de materiales escritos. Además, se presentan los significados, los papeles y las concepciones que las líderes de las CEBs atribuyen a la lectura ya la escritura, específicamente a partir de algunas historias de apropiación. Por intermedio de los procedimientos adoptados en el análisis de los datos fue posible interpretar que las diferentes formas de participación en las culturas del escrito de esas mujeres se basan en la mediación entre lo oral y lo escrito.
\end{abstract}

Palabras clave: Mujeres Campesinas, Culturas del Escrito, Letramento, CEBs, Participación Ciudadana. 


\section{Introdução}

O desejo de conhecer as trajetórias de vida de mulheres camponesas e seus percursos de formação e atuação se ancora em minha própria história de vida ${ }^{\mathrm{i}}$, pois cresci acompanhando a rotina diária de mulheres líderes de CEBs que atuavam na zona rural do município de Candiba, interior da Bahia, distante $825 \mathrm{~km} \mathrm{da}$ capital baiana. Com elas, tive meus primeiros contatos com os materiais impressos. O exercício de liderança se imiscuía nos afazeres domésticos e nas atribuições de mãe, esposa, filha e trabalhadora rural. Esse contexto, quando ainda era pequena, ensinou-me não só a valorizar o trabalho comunitário, mas também a pensar nos diversos papéis assumidos diariamente pelas lideranças que atuam na zona rural. As reminiscências das práticas culturais de leitura vivenciadas nas noites de lua cheia ou nas reuniões ao redor da fogueira e a "contação" de histórias nas rodas coletivas realizadas na casa de farinha ainda hoje permanecem vivas em mim. Muitas foram as narrativas sobre lobisomem e mula sem cabeça, as histórias bíblicas e os causos, como os de Pedro Malasarte, que ouvi.

Quanto ao mundo da escrita, a presença de livros ou de outros materiais impressos, em minha infância ${ }^{\mathrm{ii}}$, restringia- se aos didáticos de distribuição gratuita da escola ou aos materiais impressos religiosos, como jornais, boletins e cartilhas, cartazes e folhetos das Campanhas da Fraternidade, livros de cantos e catecismos ${ }^{\mathrm{iii}}$. As práticas de leitura e escrita foram motivadas pelas conversas e mediadas pela oralidade no espaço da família, da escola e da igreja. Essas lembranças se entrelaçam, dialogam entre si e compõem meu universo leitor, que acolheu e envolveu o estudo aqui exposto. De agora em diante, é utilizada a primeira pessoa do plural para apresentar um trabalho realizado a muitas mãos e a muitas vozes.

As reflexões deste texto são um recorte de uma pesquisa de doutorado a respeito de como mulheres lideranças das Comunidades Eclesiais de Base $^{\text {iv }}$ (CEBs) da Diocese de Caetité/BA ${ }^{\mathrm{v}}$, que pouco ou nunca frequentaram a escola, constroem seus modos de participação nas culturas do escrito. Ressaltamos que não pretendemos apenas descrever os modos de participação de mulheres camponesas nas culturas do escrito, mas entender como a pouca instrução escolar, a origem camponesa, a questão de gênero, o pertencimento religioso e a leitura de impressos de materiais religiosos que circulam nas CEBs fazem parte da construção desses sujeitos como leitores e escritores. 
Nesse contexto, a pesquisa indaga: em que medida os modos e as estratégias de leitura realizados nos encontros de formação de lideranças, nas famílias ou nos salões das comunidades influenciam a apropriação da leitura e da escrita? Qual o significado da leitura dos impressos para as mulheres sem nenhuma ou com pouca escolarização que atuam como líderes nas CEBs rurais da Diocese de Caetité/BA? Como determinado grupo de indivíduos, pertencente ao meio rural, participa de situações que demandam ler e/ou escrever? Que instâncias favorecem a ampliação das habilidades de leitura e escrita em contexto rural? Essas questões surgiram a partir da leitura de pesquisas sobre modos de participação de indivíduos nas culturas do escrito, pouco abordados nas publicações consultadas, e das observações realizadas no Movimento de Mulheres Camponesas da Diocese de Caetité.

Ao analisarmos os perfis de seis mulheres camponesas, constatamos que foi longa a trajetória trilhada por elas até a conquista do espaço público e religioso. Filhas de pequenos agricultores, nasceram e viveram na zona rural; nela, aprenderam desde cedo as lidas do campo. Suas infâncias foram marcadas pela religiosidade popular, pelas dificuldades de sobrevivência e pelo difícil acesso à escola. Os baixos níveis de escolaridade de
Margarida e Dália ${ }^{\mathrm{vi}}$ (terceira série do Ensino Fundamental), Acácia, Jasmim e Íris (quarta série do Ensino Fundamental), e Hortênsia (sexta série do Ensino Fundamental), não são só uma questão da chegada tardia à escola. Percebemos que a distribuição do acesso à cultura escrita para essas mulheres, além de ter sido regulada pela escolarização, foi limitada pelos fatores referentes ao âmbito social, à etnia/raça e ao gênero.

A pesquisa foi realizada em seis Comunidades Eclesiais de Base, situadas na Paróquia Nossa Senhora das Dores, localizada no município de Candiba/BA ${ }^{\mathrm{vii}}$ e vinculada à Diocese de Caetité/BA. A coleta de dados ocorreu mediante utilização da história oral, diário de campo constituído a partir dos eventos de letramento observados nas CEBs e entrevistas, com a finalidade de identificar formas de acesso e apropriação de materiais escritos - o que, por que, como e quando essas mulheres leem e escrevem. A análise documental possibilitou contextualizar e caracterizar as instituições envolvidas nesse processo de investigação, situando-as no passado e no presente.

A metodologia de investigação seguiu uma orientação dos pressupostos qualitativos de pesquisa (Flick, 2004). A compreensão dos dados fundamentou-se nos pressupostos da abordagem qualitativa, 
a qual tem estas características: interação entre o pesquisador e o objeto investigado, ênfase no processo, permissão da modificação de técnicas de coleta, releitura de questões, localização de novos sujeitos, revisão de toda a metodologia durante o desenrolar do trabalho, preocupação em retratar a visão pessoal dos participantes, trabalho de campo, descrição e indução. Tal perspectiva visa, assim, à descoberta de novos conceitos, novas relações, novas formas de entendimento da realidade (Green et al., 2005).

No texto que desenvolvemos a seguir, apresentamos estudos, pesquisas e relatos de experiências que discorrem sobre um modo de ser mulher, de participar das culturas do escrito e das práticas religiosas e sociais. Além disso, descrevemos algumas histórias de apropriação de práticas de leitura e escrita vivenciadas por mulheres camponesas, destacando como se deu sua inserção no mundo da escrita por meio de momentos distintos de interação com o objeto escrito.

\section{Mulheres, culturas do escrito e participação cidadã}

Este estudo insere-se no quadro de pesquisas a respeito dos modos de participação nas práticas culturais relacionadas à leitura e à escrita por meio de distintas instâncias de socialização.
Partimos do pressuposto de que não existe uma cultura escrita já dada, mas sim uma diversidade de culturas da escrita, que variam conforme o contexto de uso e aprendizagem. A propósito, para Marinho (2010, p. 75), "cultura escrita envolve as práticas do escrito que não são exclusivamente dependentes da língua escrita baseada no sistema alfabético".

$\mathrm{Na}$ perspectiva proposta por Galvão (2010, p. 218-220), é polêmico e complexo conceituar cultura escrita, já que o termo implica pensar algumas consequências, como o fato de essa cultura não ser homogênea. A autora afirma ser relevante pensar em culturas do escrito, pois, dessa forma, é possível entender e abarcar as diversidades de práticas e usos que envolvem o fazer cotidiano, bem como perceber os usos das culturas do escrito presentes em uma comunidade, sem, contudo, priorizar uma prática em detrimento de outras. Assim, não se trata de conceber o mundo da escrita, as práticas letradas, apenas como aquisição da habilidade de escrever; o conceito deve se estender a "todo evento ou prática que tenha como mediação a palavra escrita". (Galvão, 2010, p. 219). A pesquisadora considera a cultura escrita como "lugar simbólico e material - que o escrito ocupa em/para determinado grupo social, comunidade ou sociedade" (Galvão, 2010, 
p. 218). Entende que não existe uma cultura escrita dada a priori, mas que é possível pensar em uma diversidade de culturas escritas que se alternam a depender das necessidades e das funções do contexto de uso e aprendizagem.

A pesquisa de mestrado da primeira autora deste artigo, realizada no Programa de Pós-Graduação da Faculdade de Educação da Universidade Federal de Minas Gerais (FaE/UFMG), no período de 2007 a 2009, evidencia, por meio das práticas educativas e das tensões sociais presentes no cotidiano da Educação de Jovens e Adultos (EJA), o sistema de valores, hábitos e atitudes que permeia as vivências de homens e mulheres que buscam a escolarização, traduzindo o papel e o lugar de cada um naquele espaço (Reis, 2009). Algumas mulheres, por exemplo, queixam-se das diferentes condições das quais pessoas pouco escolarizadas dispõem para retomar a trajetória de escolarização interrompida. Outras descrevem as formas de pensar e viver, analisando os ritmos, as permanências ou as mudanças em suas trajetórias pessoais e institucionais, conforme ilustra este relato:

Só porque eu fui pra escola, meu marido se separou de mim. Eu falei pra ele: "Quando eu era criança, meu pai não me deixou estudar, agora outro homem [marido] não vai impedir". Para meu marido e meu pai era mais importante que aprendesse a usar minhas mãos que minha cabeça.
Porque eu não fiquei só usando as mãos, ou seja, lavando, passando, cozinhando, etc., o meu marido achou ruim e me largou com dois filhos. (Madalena, 32 anos). (Reis, 2009, p. 175).

A situação relatada nesse depoimento também está presente nas pesquisas realizadas no campo da EJA. As mulheres referem-se ao adiamento do sonho da educação por conta das práticas de cuidado da família e sustentação da vida que lhes são, por vezes, impostas (Bastos, 2011; Feitosa, 2005; Fonseca 2005; Nogueira, 2003).

Nossa hipótese é que, apesar de todas as restrições e as imposições de uma sociedade patriarcal, existem práticas criativas e alternativas abraçadas por muitas mulheres, seja trabalhando ao lado de seus maridos ou assumindo sozinhas as responsabilidades da família e dos filhos. Além disso, para conseguir permanecer na escola, durante $\mathrm{o}$ processo de alfabetização, elas elaboram táticas ${ }^{\text {viii }}$ para o enfrentamento das reações de seus companheiros, que as ameaçam com expulsão de casa, espancamento, constrangimentos e tentativa de desmoralização (Reis, 2009). Muitas mulheres buscam a escolarização preocupadas em obter autonomia para realizar atividades diárias que exigem leitura, visando a acabar com os constrangimentos e a dependência de outra 
pessoa e romper com a relação de dominação-exploração-submissão. Assim, vão construindo a ruptura possível.

Nas Comunidades Eclesiais de Base, no Movimento de Mulheres Camponesas (MMC) e no Movimento de Educação de Base de Iniciativa Católica (MEBIC) $)^{\mathrm{ix}}$, as mulheres se deparam com enfrentamentos e táticas que alteram o estado da não submissão. Como diz Certeau (1999), elas mudam sua maneira de fazer quando se apropriam dos espaços de outra forma, por exemplo, participando dos movimentos sociais, da Igreja e da associação de moradores. De acordo com Galvão e Di Pierro (2007, p. 16), "especialmente as que conquistaram posição de liderança comunitária e a possibilidade de fala pública, preservam a autoestima, recusam a tutela e reafirmam sua capacidade de discernimento". Esclarecedor, nesse sentido, é o comentário desta mulher:

Ser alguém eu já sou! Já sou alguém, ...mas eu quero ser alguém que sabe falar direito, porque, se a gente não sabe ler, falar e escrever sem erros, no mundo de hoje, a gente sofre..., principalmente as pessoas que são líderes de comunidade, como eu sou, e têm que ir nas repartições públicas para resolver problemas dos moradores, têm que lidar com documentos como atas, regimentos, projetos, lista de presença, tem que dar muitas assinaturas, etc., ... temos que ter a palavra fácil, ainda mais quando a líder e animadora da comunidade é negra, pobre e mulher, etc. Tem que ter sabedoria pra se virar! (Priscila, 40 anos). (Reis, 2009, p. 162).

Como elucida Priscila, sua atuação no campo religioso e na associação de moradores demonstrou-lhe a importância de buscar, na idade adulta, novas formas de estruturar o discurso oral e o escrito. Seu intuito era qualificar sua participação cidadã, integrar-se em diferentes atividades, desempenhar papéis e interagir com diversas tecnologias e instrumentos culturais.

Ela reconhece que "saber falar direito", "saber ler, falar e escrever sem erros", "lidar com documentos", "ter a palavra fácil", faz diferença na maneira de usar a leitura, a escrita e a oralidade em um contexto social de crescente marginalização de grupos que não sabem ou pouco sabem ler e escrever, dada a centralidade da escolarização e do necessário domínio da língua escrita em sociedades crescentemente "grafocêntricas". Porém, ao dizer que "tem que ter sabedoria pra se virar", ela constata que a escolarização não é a via única de acesso ao patrimônio cultural legítimo. Isso implica pensar "que passar pela escola não garante o desenvolvimento tipicamente escolar, assim como não passar por ela não impede que isso aconteça”. (Oliveira, 2009, p. 238). 
Independentemente dos anos de escolarização, Priscila acredita que as lideranças - quando dominam o uso da leitura, da escrita e da oralidade - possuem habilidades e atitudes necessárias para uma participação cidadã ativa e competente em situações em que práticas de leitura e/ou de escrita têm uma função essencial. Além disso, mantêm com os outros e com o mundo que as cerca formas de interação, atitudes e competências discursivas que lhes conferem determinado e diferenciado estado ou condição de conhecimento em uma sociedade letrada.

O relato de Priscila e de outras mulheres entrevistadas no decorrer da pesquisa de mestrado - as quais, em sua maioria, são negras, originárias de comunidades rurais, líderes das CEBs e das associações, e pouco ou nunca frequentaram a escola - suscitaram-nos algumas reflexões que, por sua vez, contribuíram para pensarmos sobre a percepção das lideranças, sobre os modos como aprendem a ler, sobre as formas como, de fato, leem. Além disso, buscamos identificar os valores que atribuem ao ato de ler, observar que atitudes são construídas em suas experiências como leitoras da Bíblia e dos materiais impressos religiosos dentro e fora da comunidade. Vale ressaltar que, como mulheres com pouca ou nenhuma escolarização, elas se relacionam com autonomia e curiosidade com os usos e as práticas da leitura e da escrita.

O estudo de Paz Albuquerque (2007) sobre a trajetória de participação e emancipação feminina de mulheres pobres na Diocese de Goiás revela que as vivências e as experiências de mulheres atuantes nas CEBs são singulares e pouco exploradas. $\mathrm{O}$ autor evidencia que as transformações religiosas da Teologia da Libertação contaram com a participação das mulheres. Reconhece que tal participação favoreceu, objetivamente, a criação de um processo pedagógico que contribuiu com mudanças subjetivas e objetivas na vida das mulheres pobres, transformações relativas à autonomia e à valorização. Dando voz a esses sujeitos, o estudo identifica um olhar e uma história feminina sobre a Diocese de Goiás e a Teologia da Libertação, reconhece a visão das participantes desse movimento. Mesmo mostrando as dificuldades encontradas pelas mulheres pobres em instituições milenarmente machistas, como a família e a Igreja Católica, os resultados da pesquisa revelam também as conquistas alcançadas por elas.

De acordo com Galvão (2010, p. 231), são quase ausentes os estudos sobre as igrejas como instâncias de difusão do escrito. As práticas religiosas exercem, no 
entanto, como já vêm mostrando alguns trabalhos, um papel fundamental na aproximação entre indivíduos e cultura escrita. Souza (2007, 2009) mostra, por exemplo, que na pequena comunidade rural que tem estudado, localizada no Norte de Minas Gerais, as únicas instâncias de circulação do escrito, além da escola, são as práticas religiosas da Igreja Católica. Silva e Galvão (2007), por sua vez, expõem o quanto a inserção em práticas religiosas pentecostais da Assembleia de Deus contribuiu para aproximar seus líderes da cultura escrita. Galvão (2010, p. 239) afirma: "Esses estudos sinalizam a necessidade de conhecer as práticas de sujeitos que são decisivos nos processos de produção e difusão do escrito e os processos de aproximação da cultura escrita de indivíduos comuns".

Estudos desenvolvidos pelo grupo de pesquisadores de Santa Bárbara, pertencente à Universidade da Califórnia, "concebem o letramento como um fenômeno social que é situacionalmente definido e redefinido por meio da interação de diferentes grupos sociais incluindo grupos de leitura, famílias, salas de aula, escolas, comunidades e grupos sociais" (Castanheira et al., 2001, p. 354). Como processo, o fenômeno do letramento só pode ser percebido nas ações dos sujeitos, nas orientações de suas atitudes, nas expectativas dos indivíduos e, por último, na forma como eles interagem, interpretam e constroem os textos.

As mudanças nas práticas socioculturais dos indivíduos têm suscitado discussão sobre o que significa ser letrado. Com relação a esse debate, Street (1984) já defendia há 30 anos que letramento é mais do que a capacidade de decodificar para compreender sentidos expressos em uma página, em uma tela de computador ou, ainda, em uma prática social situada. Barton e Hamilton (1998) consideram que o letramento permite ao indivíduo apoderar-se de um conjunto de habilidades e conhecimento e participar, efetivamente, de todos os eventos da comunidade a qual pertence e das tradições, dos hábitos e dos costumes com os quais se identifica.

Também o levantamento sobre "Letramento e Alfabetização de Jovens e Adultos", feito por Vóvio e Kleiman (2013) na primeira década do milênio, assinala que há muitos estudos e pesquisas sobre "letramento e alfabetização" e "letramento e escolarização" e poucos trabalhos relacionados com o letramento fora do âmbito escolar ou ligados a grupos específicos, práticas situadas e locais. As autoras mostram que "as práticas de letramento que os sujeitos compartilham e as aprendizagens que desenvolvem nem 
sempre resultam na ampliação de modos de ação e de inserção em sociedades grafocêntricas". (Vóvio \& Kleiman, 2013, p. 193).

Diante da complexidade inerente aos sentidos e aos modos como programas de alfabetização de jovens e adultos têm se concretizado no Brasil, esta pesquisa tem como propósito entender como sujeitos tradicionalmente associados à oralidade constroem, ao longo de suas trajetórias de vida, modos de participação nas culturas do escrito. Por isso, ao centralizar o foco deste estudo em processos educativos não escolares, geramos subsídios para melhor compreender o papel ocupado pelas instâncias religiosas populares (no caso, as católicas) na formação de mulheres e seus processos de aproximação com a leitura e a escrita.

De acordo com Souza (2007), estudos que atualmente se ocupam da descrição dos modos de uso do escrito, das formas de participação de sujeitos, famílias e grupos sociais na cultura escrita, e das implicações dessa participação têm se esforçado em compreender, por exemplo, o que as pessoas fazem com a escrita. Nessa direção, pesquisas realizadas no Brasil por Galvão (2001, 2004) evidenciam formas particulares de participação de indivíduos no mundo da escrita. A autora chama a atenção para percursos de sujeitos singulares, cujo contato e experiência com a escrita ocorrem fora do processo de escolarização, como as "experiências de leitura coletiva e em voz alta de folhetos de cordel" e as leituras de "legendas do cinema”. (Galvão, 2004, p. 147).

Segundo Abreu (2002), se, por um lado, já conhecemos bem como são os modos de ler, o acesso a materiais escritos, os motivos pelos quais se lê e os espaços dados à leitura dos grupos culturais de prestígio - se já temos consciência da história dos livros canônicos e do modo como acontece a aprendizagem e a disseminação da leitura escolar -, por outro, não foram pesquisadas, de modo satisfatório, as formas de contato com os livros e os materiais escritos. Além do mais, pouco sabemos sobre os objetos e as práticas de leitura em circulação entre grupos desprestigiados, a exemplo das populações camponesas. Dessa forma, parece-nos importante entender como a pouca instrução escolar, a origem camponesa, a questão de gênero e o pertencimento religioso contribuem nos modos de participação nas culturas do escrito de mulheres camponesas líderes das CEBs.

\section{Práticas de leitura e escrita de mulheres camponesas}


As práticas de leitura e escrita desenvolvidas nas CEBs, no sindicato, na Pastoral da Criança, na associação, no Movimento de Mulheres Camponesas, em suas residências com seus filhos e em tantos outros espaços abrangem as inúmeras vivências das mulheres camponesas. Essas experiências não se relacionam apenas ao espaço escolar, pois suas atividades de leitura e escrita se constituem considerando as diferentes demandas sociais.

Acácia e Íris, por exemplo, vivenciam, na Pastoral da Criança, diversificadas práticas de letramento regularmente implementadas. Estas dizem respeito aos usos da leitura e da escrita com os seguintes objetivos: comunicar; organizar e requerer a execução de ações; e atribuir significados às atividades que desenvolvem durante a visita domiciliar, ao atendimento às crianças menores de 6 anos, à celebração da vida, ao acompanhamento das famílias e da comunidade, à reunião de reflexão e à avaliação das atividades realizadas.

Outras experiências do ler e do escrever realizadas por Acácia referem-se ao acompanhamento das gestantes da Pastoral da Criança por meio do instrumento "Laços de amor". A cada mês, as gestantes recebem uma cartela com as principais informações sobre 0 desenvolvimento do bebê, as alterações no corpo da mulher e os incentivos para que façam seu pré-natal. São mensagens que melhoram a autoestima da futura mãe e fazem com que ela acompanhe, mês a mês, o desenvolvimento de seu filho e tenha em vista os cuidados que deve ter com sua gestação.

Vale lembrar que as atividades da Pastoral da Criança são fortemente marcadas pela oralidade, pela leitura e pela escrita, além de ser representadas de modo intenso por um fazer que se aprende e se adquire com o outro, em contextos culturais específicos, que requerem participação, atividade e ação. Citamos a seguir uma prática registrada no diário de campo, realizada no Centro Comunitário São José:

Hoje é dia de "Celebração da Vida". Neste dia, as famílias e as líderes se reúnem para avaliar o desenvolvimento de suas crianças, trocar experiências e celebrar os resultados alcançados. A comunidade organizou a celebração no salão comunitário, ao ar livre, debaixo das árvores. As líderes pesam as crianças e compartilham um lanche em clima de festa. Enquanto as crianças são pesadas, o peso é registrado na caderneta da criança, para controle da família, e no Caderno do Líder, para posteriormente ser enviado à Coordenação Nacional da Pastoral da Criança. $\mathrm{O}$ encontro é enriquecido com brincadeiras com as crianças. A espiritualidade está presente por meio da mística. (Diário de campo, 26 ago. 2012). 
Todas as atividades realizadas por Acácia e Íris e por demais líderes são, ao final de cada visita domiciliar, anotadas e registradas em relatórios que, em seguida, são endereçados à equipe paroquial da Pastoral da Criança para, posteriormente, alimentar os dados da Coordenação Nacional da Pastoral da Criança e para comprovar os serviços prestados. Em se tratando de eventos de letramento, a construção desses relatórios, resultado das atividades realizadas, constitui-se em uma prática situada, inerente ao âmbito social do trabalho dessa associação. A efetivação desse tipo de prática se instaura como um evento de letramento que, na visão de Barton e Hamilton (1998), assume caráter formal por se efetivar por meio de procedimentos adotados por uma agência de assistência social, neste caso, as equipes da Pastoral da Criança.

$\mathrm{Na}$ comunidade de Jasmim, observamos a realização de um círculo bíblico coordenado por ela. A temática do encontro foi "O problema das divisões dentro da Comunidade”. Inicialmente, Jasmim fez uma introdução dizendo que, na primeira carta aos Coríntios, o que mais preocupa Paulo são as divisões no interior da comunidade. Segundo ela, essa inquietação percorre toda a carta, mas recebe uma atenção especial nos quatro capítulos iniciais. Contextualizando a leitura, ela disse que "o mesmo problema ocorre hoje em muitas das nossas comunidades". Enfatizou que há tensões e divisões que dificultam a vida de muitas pessoas bem-intencionadas. Porém, para ela, o que chama a atenção na carta de Paulo é o carinho e, ao mesmo tempo, a firmeza no jeito de ensinar que utiliza para discutir o problema das divisões em busca de uma solução. Ressaltou que "o jeito de Paulo pode nos ajudar na busca de uma solução para os problemas que hoje enfrentamos nas nossas comunidades".

Após a introdução do encontro, solicitou aos participantes que localizassem, na Bíblia, o trecho "1Cor 1,1-16". A leitura foi feita em voz alta por uma das pessoas presentes; enquanto isso, as demais acompanharam a narração silenciosamente. Depois, Jasmim propôs aos participantes uma reflexão sobre a leitura a partir do método Ver, Julgar $e$ Agir. Tendo como pressuposto o Ver, questionou: "Olha de perto, o que estava acontecendo lá na comunidade de Corinto?". Houve vários comentários fundamentados no texto. Jasmim, então, provocou o grupo perguntando: "Hoje, nas nossas comunidades acontece algo semelhante?". Após as falas, Jasmim dividiu o grupo em duplas e propôs a troca de ideias a partir destas interrogações: “ 1 . Estes problemas de divisão acontecem em 
nossa comunidade elou em nossas famílias? 2. Por que será que nascem tantas divisões, quando todos parecem querer o bem comum? 3. O que nós estamos fazendo para criar mais unidade?".

Depois da partilha feita pelas duplas, iniciou-se o segundo momento do círculo bíblico, chamado de Julgar, que, para Jasmim, é a ocasião de iluminar a situação da comunidade a partir do texto bíblico. Desse modo, ela propôs novamente a leitura lenta e atenta do 1Cor 1,1-16. Pediu que, enquanto lessem, ficassem com esta questão na cabeça e no coração: “Quais as sugestões de Paulo para superar as divergências nas nossas comunidades $e$ nas nossas famílias?". Houve um momento de silêncio e, posteriormente, Jasmim sugeriu aos participantes que trocassem ideias em grupo para descobrir qual a luz do texto bíblico para a atualidade a partir das indagações: “ 1 . $O$ que mais chamou sua atenção nas palavras de Paulo? 2. Quais as sugestões de Paulo para superar as divergências? 3. Qual a luz que encontramos para iluminar os problemas da nossa comunidade?’.

Assim que os participantes acabaram de falar, Jasmim fez a seguinte reflexão:

Ler e meditar as cartas de Paulo pra mim é buscar caminhos para evangelizar e viver o hoje com coragem e sabedoria ... Muitas pessoas deixaram a roça e foram morar na cidade, atraídos pela propaganda e pelos sonhos de uma vida melhor. Na roça, a vida não é fácil, o trabalho na agricultura é pesado, mas acho que a vida aqui não é pior do que na cidade ... A fé aqui é transmitida dentro da família, há solidariedade entre nós, e os filhos acompanham os pais na vida e na religião ... Para os que saem da roça e vão pra cidade cheios de esperanças, a vida na cidade se torna um pesadelo. Tudo é muito apressado. Não sobra tempo para conversar e conviver. Na cidade, quem não tem trabalho não tem dinheiro. Sem dinheiro numa cidade se morre de fome. Por outro lado, com dinheiro se consegue tudo aquilo que a cidade oferece em termos de consumo. A cidade produz uma mudança na cabeça das pessoas. Os filhos se adaptam mais rápido que seus pais à vida da cidade e não aceitam mais o modo de viver e de agir deles. Não seguem mais o comportamento religioso dos pais. Abandonam a fé e buscam novas formas de viver a religião. E numa cidade o que não falta são propostas religiosas e Igrejas. $\mathrm{Na}$ verdade, a cidade é um grande mercado religioso, onde as pessoas escolhem a religião que mais lhes agrada ... (Síntese das anotações da fala de Jasmim. Diário de campo, 30 jun. 2012).

No terceiro momento do círculo bíblico, denominado Agir e Celebrar, Jasmim solicitou ao grupo a sistematização em uma frase ou palavra do que havia sido refletido no encontro. Por fim, os participantes formularam preces espontâneas com a intenção de agradecer a Deus pela vida, pelas aprendizagens daquele dia e pelos compromissos assumidos. Alguns deles escreveram as 
preces em papeizinhos, uns as leram em voz alta, enquanto outros as depositaram em uma caixinha. Todos rezaram um salmo na Bíblia e encerraram a reunião com a oração do Pai Nosso e do canto final.

Ao focalizar o letramento no espaço religioso, concebemo-lo como um fenômeno não apenas situado, mas também como múltiplo, visto que sua efetivação é motivada pelos inúmeros usos da leitura e da escrita estabelecidos em atendimento às demandas de comunicação que ocorrem em uma prática religiosa de letramento. Notamos que tal prática, em contextos rurais, está presente nas comunidades com os modos de participação que a Igreja propõe e com a orientação cristã. Esta é dada pelo representante da Igreja, como participante da equipe de liturgia, e principalmente pelo padre, os dois assumem a voz dessa instituição, respaldada no texto escrito "sagrado".

O culto dominical, o evento religioso mais frequente na Igreja Católica e na comunidade, consiste na leitura do folheto "O Domingo", produzido pela editora Paulus, que tradicionalmente publica textos católicos. Esse folheto de quatro páginas contém leituras litúrgicas para cada domingo, proposta de reflexão, cantos do hinário litúrgico da CNBB e artigo com o tema do dia ou o acontecimento eclesial.
Observamos a celebração do culto dominical na comunidade de Hortênsia. Na ocasião, segundo ela, havia cinco equipes de liturgia, e ela participava de uma destas. A leitura do folheto é feita pelos membros da equipe de liturgia, que assumem os papéis de leitores, comentaristas e dirigentes, de acordo com sua organização. A assembleia participa do culto conforme a indicação feita no próprio folheto, assim como o faz no momento dos cantos. As práticas de letramento, nesse contexto, estão convencionadas por um ritual, o qual requer modos de participação específicos e práticas regulares em torno do texto escrito.

Outro evento religioso do qual Hortênsia participa é a catequese. Esta acontece semanalmente, e dela participam crianças, adolescentes, jovens e adultos. As pessoas da própria comunidade, voluntariamente, prestam serviço à catequese. Segundo Hortênsia, em geral, há mais catequistas mulheres que homens. Elas são preparadas em alguns encontros na paróquia e cada uma trabalha com um grupo separado por faixa etária. Adota-se um livro predeterminado pela paróquia, o qual norteia o trabalho. A propósito, a seguir, descrevemos um encontro realizado com 33 crismandos, com idades entre 14 e 20 anos, no dia 10 de novembro de 2012. 
Inicialmente Hortênsia propôs um momento de oração espontânea e, logo após, apresentou oralmente a temática do quinto encontro: "Deus Chama Abraão". No primeiro momento, chamado "Olhando a vida", expôs, em um cartaz, a imagem do Brasil ilustrando o latifúndio (Figura 1) e perguntou aos crismandos: "Qual a realidade dramática que o desenho exposto quer mostrar?’.

Figura 1 - Latifúndio no Brasil.

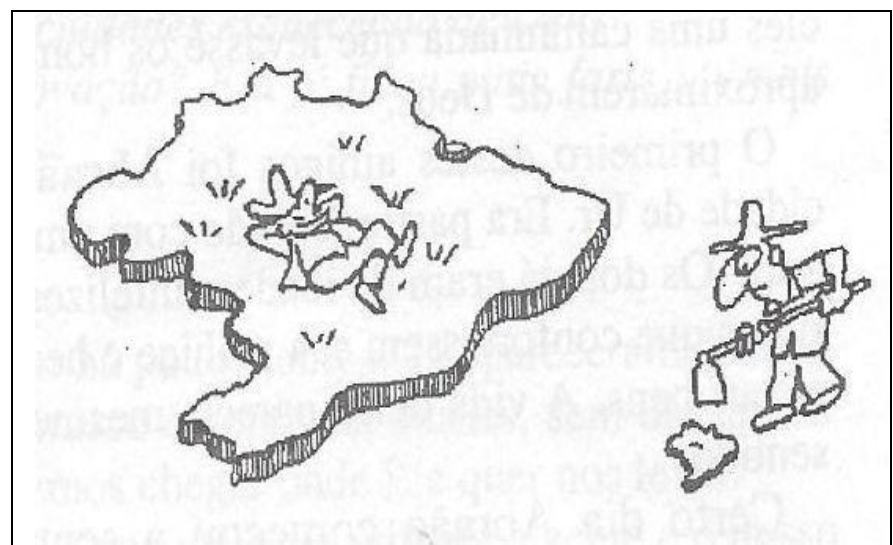

Fonte: Adaptado de Bucciol (2004, p. 17).

Em seguida, apresentou outro cartaz

organizado da seguinte forma pela

catequista:

Figura 2 - Maneira de dividir as terras no Brasil.

\begin{tabular}{|c|c|}
\hline \multicolumn{2}{|c|}{ AS TERRAS NO BRASIL ESTÃO DIVIDIDAS MAIS OU MENOS ASSIM! } \\
\hline \multicolumn{2}{|c|}{ Um homem distribuiu 100 hectares de terra entre 100 agricultores. Ele deu: } \\
\hline 45 hectares & 1 agricultor \\
\hline 34 hectares & 9 agricultores \\
\hline 18 hectares & 37 agricultores \\
\hline 3 hectares & 54 agricultores \\
\hline \multicolumn{2}{|c|}{ REFLEXÃO: O que vocês acham dessa maneira de dividir a terra? } \\
\hline
\end{tabular}

Fonte: Adaptado de Material da catequista.

Após isso, a catequista Hortênsia convidou os crismandos para cantar e prestar atenção às palavras da música "Não há, ó gente, ó não/ Luar como este do sertão". Quando terminaram de cantar, perguntou ao grupo: "Entre má distribuição da terra e da renda, injustiças sociais, pobreza, etc., e migração, existe ligação? Por quê??". Houve significativa participação dos jovens, que realizaram 
inferências, por meio do conhecimento prévio, dos saberes da experiência de migração na família e na comunidade, para interpretar os textos apresentados; pediram esclarecimento sobre questões desconhecidas e anotaram as informações apresentadas.

No segundo momento do encontro, intitulado "Procurando na Bíblia", foi distribuído e lido de forma compartilhada um texto escrito com a história de Abraão. Após a leitura deste, Hortênsia introduziu a terceira parte da reunião, chamada "Voltando à vida", convidando os crismandos para conversar em grupos, por 15 minutos, a partir das seguintes questões:
1. O que nos pode ensinar a história de Abraão? 2. Será que Deus gostaria de dar a cada lavrador uma terra como a Abraão? 3. Então, por que existem tantos lavradores sem terra? 4. Quais as dificuldades da vida que mais desanimam a gente? 5 . Procuramos, às vezes, resolver as dificuldades esquecendo de Deus? 6. A nossa fé já passou por alguma provação? E a fé ficou mais forte ou mais fraca? (Diário de Campo, 10 nov. 2012).

A socialização da conversa na plenária foi participativa. Utilizando o livro Canta Povo de Deus (Bucciol, 2007), entoaram o canto "O Senhor me chamou a trabalhar". Por fim, a catequista apresentou e discutiu os compromissos da semana.

Figura 3 - Compromissos dos Crismandos.

\section{COMPROMISSOS:}

1. A caminhada do nosso grupo começou há pouco tempo. Já apareceram dificuldades? Alguém desistiu? Nosso compromisso é continuar firmes, sem desanimar porque temos confiança em Deus e queremos chegar onde Ele quer nos levar.

2. Procurar descobrir algumas dificuldades que mais desanimam a gente e o nosso povo e ver como é possível resolvê-las sem esquecer de Deus.

Fonte: Adaptado de Bucciol (2004, p. 19).

Diante do exposto, compreendemos que os eventos de letramento promovidos pela Igreja Católica podem ser definidos como práticas de letramento, uma vez que são regulares na comunidade e contribuem para a construção de padrões culturais de uso da leitura e da escrita (Barton, 1994). $\mathrm{O}$ culto e a catequese, além de serem uma prática de letramento regular, contribuem para a manutenção de uma identidade religiosa local. Hortênsia relatou que, em sua comunidade, "as pessoas participam do culto nos finais de semana e, também, da catequese, porque ali se sentem um grupo, um nós".

Outra prática de leitura observada ocorreu no encontro de crismandos e foi realizada por Margarida no dia $11 \mathrm{de}$ 
novembro de 2012, na comunidade de

Dourado, como retratado no seguinte

trecho do diário de campo:

Inicialmente, Margarida fez um momento de relaxamento com o grupo de crismandos. Em seguida, invocou o Espírito Santo de Deus e pediu sua ajuda. Margarida explicou que segue os passos aprendidos com as freiras. No primeiro momento, cada um dos crismandos pegou sua Bíblia e leu com calma o texto bíblico; leu, releu, tornou a ler, até conhecer bem o que estava escrito, até assimilar o próprio texto. Depois, fecharam a Bíblia e fizeram um momento de silêncio interior, lembrando-se do que leram. Os jovens partilharam oralmente suas impressões em relação ao texto repetindo palavras, frases, versículos ... Margarida disse: "agora já não é mais só o que o texto diz, mas o que esta Palavra está dizendo a cada um de nós dentro da realidade em que estamos vivendo. $O$ que Deus falou no passado e o que está falando hoje, através deste texto? $O$ que o texto diz? [pediu aos jovens para levar o texto para a própria vida e para a realidade pessoal e social] $O$ que Deus está me falando?". Falou aos crismandos que a leitura e a meditação da Palavra se transformam em um encontro íntimo e pessoal com Deus. Prosseguindo, perguntou aos crismandos: "O que o texto bíblico e a realidade de hoje nos motivam a rezar". Nesse momento, propôs a oração pessoal, expressão espontânea de nossas convicções e sentimentos mais profundos. $\mathrm{E}$ perguntou: "O que o texto me faz dizer a Deus? [Rezar - suplicar, louvar, dialogar com Deus, orar...]". Após esse momento, Margarida sugeriu a contemplação, que, para ela, não é algo que se passa na cabeça, mas é um agir novo que envolve todo nosso ser. Encerrou o momento de leitura orante da Bíblia com os questionamentos: "a partir deste texto como devo olhar a vida, as pessoas, a realidade... O que devo fazer de concreto? O que ficou em meu coração e me desperta para um novo modo de ser e agir?". Solicitou aos crismandos que registrassem no caderno e, por fim, sugeriu que escolhessem uma frase para memorizar. (Diário de campo, 11 nov. 2012).

Margarida relatou que, com os padres, as freiras e as companheiras de caminhada, aprendeu a fazer a leitura orante da Bíblia, prática que realiza individual e coletivamente, principalmente em momentos de retiro e adoração. É pertinente destacar a importância que o tio, as freiras e os padres tiveram na história de vida de Margarida, instigando-a, sobretudo, por meio do exemplo a aprofundar-se na prática da leitura. O trecho a seguir ilustra bem nossas afirmações: "Não esqueço do meu tio Abílio, que aprendeu a ler sozinho e foi quem alfabetizou os filhos e muitos sobrinhos e outras pessoas da comunidade. Era um homem sábio". De acordo com a fala de Margarida, entendemos que a relação entre as práticas de leitura e escrita ensinadas $\mathrm{e}$ as adquiridas não se dá de forma linear, mas sim ocorre em função do contexto religioso em que elas aparecem.

Para Acácia, uma das originalidades das CEBs é articular a leitura da Bíblia e as celebrações com as lutas populares e os 
movimentos de melhoria das condições de vida e trabalho do povo, principalmente, no campo e na periferia. De acordo com a entrevistada, os desafios atuais da Igreja nos convidam a redescobrir o gosto de compartilhar a vida com o outro na dinâmica da alteridade, fazendo da comunidade cristã o espaço para fortalecer a amizade, a partilha e a comunhão fraterna. Vejamos a fala de Acácia:

\begin{abstract}
Rezar não é só rezar ao levantar, ao dormir, vai muito além: é transmitir a vida para outras pessoas no dia a dia. Falar com o companheiro pra dividir a marmita com quem não tem almoço, isso é rezar ... Eu rezo quando tô na Igreja e quando tô denunciando as injustiças e o salário baixo, porque aí não rezo só pra mim, mas rezo pra outros... Reunião do Círculo Bíblico é oração, quando a gente consegue uma vitória, é oração ... O amor e o louvor a Deus não devem ser expressos só no culto, mas na vida de cada dia... $\mathrm{Na}$ minha opinião, de nada adianta muita reza se não nos ajudamos uns aos outros, por isso vejo a necessidade de participar de associações, de sindicato e politicamente. Se, por um lado, esta é a parte mais difícil, a mais delicada e a mais arriscada, a que pode gerar mais divisões $\mathrm{e}$ conflitos, por outro lado, é a mais importante, por causa do bem coletivo que através dela a gente pode conseguir.
\end{abstract}

Recorrendo a Chartier (2001), compreendemos que essas "figuras de leitura" dizem respeito a estilos próprios que revelam as relações existentes entre o leitor e o objeto lido. Podemos contrastar essas formas de ler, nas quais as quantidades de acesso à leitura e as diversas formas de apropriação determinam suas especificidades e seus resultados. Chartier define esse estilo de leitura, que se dá de forma repetida, memorizada, reconhecida, como prática de "leitura intensiva". Para o autor, há uma relação atenta e diferente entre o leitor e aquilo que este lê, "incorporando em seu ser mais íntimo a letra do que leu" (2001, p. 86-89). A leitura intensiva é, pois, entendida como "uma maneira de ler que assegura eficácia ao texto, graças a um trabalho de apropriação lento, atento e repetido" (2001, p. 89).

É comum nas CEBs, nos sindicatos, no Movimento de Mulheres Camponesas, nas associações e nos outros espaços observados durante a pesquisa, uma ênfase em outros modos de práticas comunicativas, como expressões visuais, sonoras, táteis entre outras, que se unem à palavra escrita ou falada. É o evento da multimodalidade, que mostra, por meio de diferentes modos de representação discursiva, novas possibilidades para as diferentes ordens de comunicação.

Desse modo, as práticas de letramento ganham corpo, materializam-se nos diversos eventos de letramento dos quais as mulheres líderes das CEBs participam cotidianamente. Os textos 
multimodais ${ }^{\mathrm{x}}$, entre eles os retratados nas Figuras 4 e 5, apresentados na comemoração dos 25 anos da Pastoral da Criança na Diocese de Caetité/BA proporcionaram interação entre os participantes e seus processos interpretativos. Com essas exposições, os

Figura 4 - Foto do Aniversário dos 25 anos da Pastoral da Criança na Diocese de Caetité/BA.

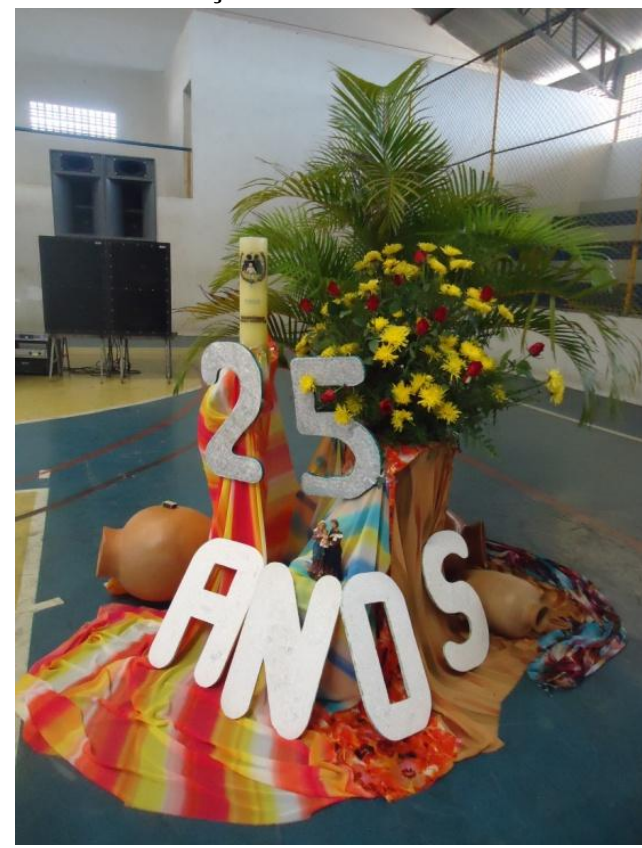

Fonte: Arquivo da pesquisa (2/06/2012).

As figuras 4 e 5 expõem um evento de letramento em que o texto escrito não aparece sozinho, autonomamente, como linguagem, está relacionado a símbolos e imagens que contribuem para a atribuição de significados. No ato da construção de um dado texto - seja ele escrito, oral e/ou imagético -, o autor pode fazer uso de uma vasta quantidade de recursos linguísticos multimodais provenientes tanto do plano verbal como do visual. Todos esses espaços internos das Igrejas e salões comunitários ganham vida por meio dos textos multimodais e desafiam os participantes a repensar as concepções enunciativas de produção e leitura de enunciados.
Figura 5 - Foto do Aniversário dos 25 anos da Pastoral da Criança na Diocese de Caetité/BA.

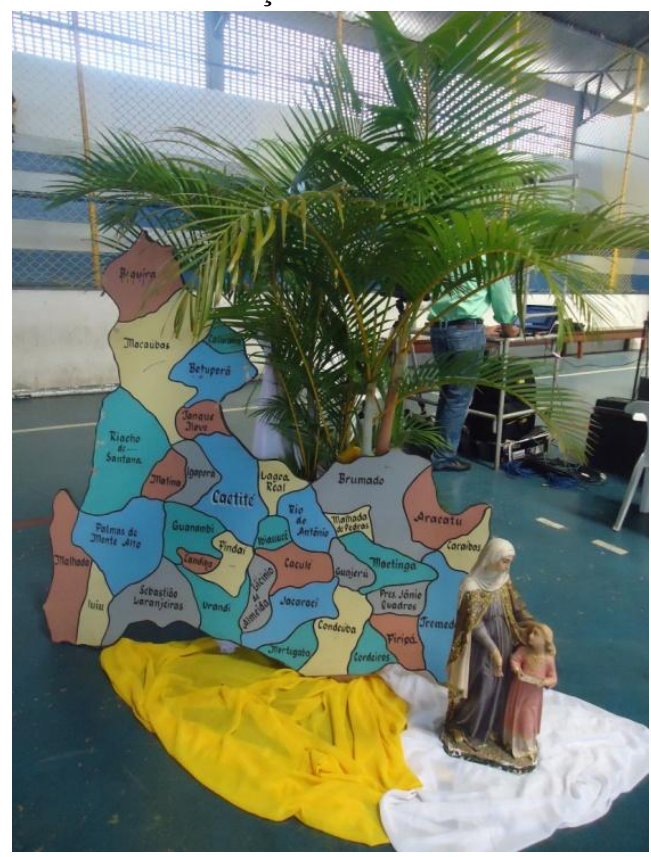

Fonte: Arquivo da pesquisa (2/06/2012).

distintos modos de construir um texto acarretam modificações substanciais na forma como as pessoas elaboram sentido e significação, transcendendo, dessa maneira, a primazia dada à palavra. A multimodalidade propicia, então, o irromper de diversificados recursos de construção de sentido.

Nesse contexto, a multimodalidade refere-se às mais distintas formas de representação utilizadas na construção 
linguística de uma dada mensagem, tais como: palavras, imagens, cores, formatos, marcas/traços tipográficos, disposição da grafia, gestos, padrões de entonação, olhares etc. Segundo Rojo (2012), ela não é apenas a soma de linguagens, mas também é a interação entre linguagens diferentes em um mesmo texto.

A multimodalidade abrange, portanto, a escrita, a fala e a imagem. Cabe mencionar que em todos os salões comunitários onde as mulheres entrevistadas realizam e/ou participam de encontros e celebrações há quadro de avisos nos quais são expostas a programação da comunidade e a prestação de contas de entradas e saídas dos recursos do dízimo e demais ofertas. Observamos também a exposição de cartazes e varal, nos quais são expostas algumas atividades produzidas pelas crianças, pelos adolescentes e pelos jovens da catequese, o que interpretamos como uma forma de valorização de seus trabalhos.

As mulheres entrevistadas nesta pesquisa lidam com textos cada vez mais multimodais, que exigem delas estratégias de escrita e leitura que estejam de acordo com a multiplicidade de linguagens que compõem o texto. Jasmim explicou que o uso de filmes nos encontros da comunidade desperta ou até mesmo conduz o "leitor" para a realidade vivida por aquelas pessoas neles retratadas, citou como exemplo o filme Anel de Tucum (Berning, 1994). Rojo e Moura (2012) afirmam que o desenvolvimento das tecnologias da comunicação, com suas práticas sociais específicas de leitura e escrita, exige que as instâncias formadoras se foquem nessa realidade e partam dela para ensinar.

No período de produção de material empírico para esta pesquisa, observamos vários eventos de letramento em que as mulheres utilizavam filmes para discutir algumas temáticas nos encontros. Segundo Jasmim, essa prática, além de evocar sentimentos e sensações nos participantes, possibilita conhecer determinada experiência, dando a impressão de integração a essa vivência.

No dia 19 de agosto de 2012, por exemplo, acompanhamos, na comunidade de Jasmim, a exibição do filme $O$ Anel de Tucum (Berning, 1994), que retrata o cotidiano dos homens e das mulheres que fazem das Comunidades Eclesiais de Base e dos movimentos populares uma realidade. O longa-metragem se passa em 1992, mesmo ano em que ocorreu o oitavo Encontro Intereclesial de Comunidades de Base em Santa Maria/RS, inferimos esse dado a partir da cena em que o personagem principal, André, aparece em um orelhão e, 
ao fundo, estão expostos os cartazes do encontro.

O filme pode ser dividido em dois momentos, que se misturam no transcorrer da exibição. O primeiro é uma narrativa ficcional com personagens e roteiros criados. Já o segundo é formado por partes documentais; os integrantes destas pertenciam aos movimentos populares e às Comunidades Eclesiais de Base, eram lideranças religiosas e ganhavam voz (Diário de campo, 19 ago. 2012).

Antes da exibição, Jasmim fez uma breve contextualização, visando motivar o grupo. Após essa apresentação, houve um momento de debate a partir das seguintes questões:

de acordo com o filme, quem está por trás da mobilização do povo nas pastorais comprometidas nessa caminhada de libertação que marcou a Igreja do Brasil, da América Latina? A Igreja deve se preocupar com o lado espiritual ou com as necessidades materiais do povo? $\mathrm{O}$ pensar e o agir politicamente que o filme coloca é um desafio não só do momento histórico em que foi gravado, mas também dos dias atuais. A Igreja, os padres e os fiéis devem se negar a participar do debate político? Devem somente tratar dos males que afligem a alma? (Diário de campo, 19 ago. 2012).

No salão comunitário onde foi exibido o filme, foram expostos em cartazes vários fragmentos das falas dos personagens e recortes dos depoimentos das falas de Dom Luciano e Dom Pedro Casaldáliga. Um dos participantes, por exemplo, ao refletir sobre a poesia e retomar as discussões motivadas pelo material Anel de Tucum, disse: "o Evangelho prioriza o direito dos pobres $e$ o capitalismo não, o Evangelho propõe a solidariedade $e$ o capitalismo $a$ competitividade ...". Ele concluiu afirmando que o Evangelho é um texto e uma prática radicalmente anticapitalista $\mathrm{e}$ que, se Jesus vivesse hoje, seria caracterizado como "de esquerda", porque, em sua época, foi contra o poder político e religioso (Diário de campo, 19 ago. 2012).

Nesse contexto, Jasmim falou de seu desejo de ver uma verdadeira revolução na Igreja Católica, a começar pela aplicação das decisões do Concílio Vaticano II, que ocorreu há mais de 50 anos e ainda hoje não foram implementadas. Estas envolvem, por exemplo, maior democratização da Igreja; dessa forma, o povo de Deus seria protagonista e não ovelha a ser tosquiada. Além disso, Jasmim espera que se acabe com o celibato obrigatório, sejam permitidos o sacerdócio das mulheres e a reinserção no ministério sacerdotal dos padres casados que queiram voltar e se faça uma profunda revisão da moral sexual da Igreja (Diário de campo, 19 ago. 2012). 
Jasmim lembrou que, quando a Teologia da Libertação e as CEBs eram mais valorizadas pela Igreja no Brasil, os templos estavam cheios. Depois que começaram a ser discriminadas e reprimidas, dando lugar ao espiritualismo do "aleluia, aleluia", os templos começaram a esvaziar. Então, perguntou: “quem tem culpa? Quem está esvaziando a Igreja? A Teologia da Libertação ou essa Igreja espiritualista que fica de frente para Deus e de costas para os pobres?" (Diário de campo, 19 ago. 2012).

$$
\text { Jasmim disse que olha }
$$
constantemente para a lua, as estrelas, o crucifixo, e afirmou:

Sei que Deus me conhece e sabe quem eu sou, isso me basta ... A gente vê Deus com os olhos interiores ... Deus é como o ar que respiramos, a gente não vê Deus, mas sente; e sem o ar não podemos viver, também a gente não pode viver sem Deus. Acho que toda vez que a gente sente entusiasmo de levantar de manhã e ter de começar o dia, ter capacidade de estender a mão ao outro... Deus está ali, porque Deus não é um objeto, Deus é uma suprema paixão, suprema energia... É muito bom ter um Deus dentro, que nos ama e caminha com a gente. (Jasmim, 53 anos).

Jasmim lamentou, ainda, o aumento do poder de pressão e da influência dos evangélicos na seara política. Ela teme que alguns destes, não todos, “estejam chocando o ovo da serpente". Já que eles não podem impor, por meio de sua pregação, sua moral e seus costumes ao conjunto da população; então, buscam o poder político, porque pela lei podem tornar qualquer decisão universal (Diário de campo, 19 ago. 2012).

Nessa direção, outro participante do grupo expressou seu desejo de ver acontecer uma reforma política profunda no Brasil: "precisamos deixar de ser objetos de campanhas eleitorais de dois em dois anos, e passar a ser protagonistas". Reconheceu a importância dos direitos pessoais concedidos pelo governo, como a facilidade de crédito e o acesso à moto e ao carro, mas lamentou a não obtenção dos direitos sociais, que basicamente consistem em segurança, alimentação, moradia, saúde e educação (Diário de campo, 19 ago. 2012).

Já Acácia e Íris utilizam, nos encontros da Pastoral da Criança, os materiais radiofônicos que recebem: programa Viva a Vida; entrevistas; spots, vinhetas e jingles; $\mathrm{CD}$ com músicas da Pastoral da Criança; e jornal de apresentação da Pastoral da Criança. O programa de rádio Viva a Vida é semanal, possui 15 minutos de duração e veicula temas sobre saúde, nutrição, educação, direitos, organização comunitária, entre outros assuntos de interesse de seu público (Diário de campo, 3 mar. 2012). 
Diante do exposto, compreendemos as práticas de letramento como atividades que devem ser pensadas de forma ampla. Consideramos que os usos das tecnologias permitem que atividades aparentemente orais sejam marcadas por representações próprias da escrita. Ouvir uma notícia em um programa de rádio, por exemplo, como aborda Kleiman (2008), é um evento de letramento, tendo em vista que o texto ouvido tem as marcas típicas da modalidade escrita.

Para analisar a forma como os membros das comunidades estudadas utilizam a escrita, tivemos que identificar e caracterizar os diversos contextos situacionais nos quais esses indivíduos fazem uso da escrita. No âmbito religioso, notamos os usos que os membros das CEBs fazem da escrita dentro do ambiente de sua comunidade. Kleiman (2008) explica que, a partir do momento em que os estudos deixam de tomar como universais os efeitos das práticas de uso da escrita e passam a analisar esses efeitos por meio de práticas sociais e culturais de diferentes grupos, ocorre um alargamento do conceito de letramento.

\section{Considerações finais}

Os resultados da pesquisa revelaram que as mulheres encontraram nas participações dos movimentos sociais, das CEBs da Igreja Católica, dos partidos políticos e dos sindicatos, sentido, motivos e mesmo condições para enfrentarem as discriminações de gênero, as desigualdades de poder existentes na família e no espaço público dos movimentos sociais e da Igreja. A experiência de participação das líderes das CEBs nesses espaços formativos apresenta-os como possíveis agências de letramento.

Nesse contexto, as Comunidades Eclesiais de Base surgem como espaços de fortes laços de solidariedade e de formação da consciência crítica das camadas pobres. Nesses espaços, as pessoas começam a expressar suas opiniões e angústias do dia a dia. Como diz o refrão de um canto bastante conhecido das CEBs: "De repente nossa vista clareou, clareou, clareou. Descobrimos que o pobre tem valor, tem valor, tem valor" (Diário de campo, 29 abr.2012). A comunidade é o lugar da autoestima; nela as pessoas se sentem valorizadas e encorajadas a enfrentar seus problemas pessoais de forma coletiva. Como diz Durkheim (2002), o indivíduo ganha sua força e sua vida no coletivo, sua forma de religiosidade é fortemente centrada nos aspectos coletivos.

As mulheres participam de novas esferas de atividades e interagem com diferentes usos da leitura e da escrita. 
Percebemos que as CEBs possuem um papel importante para promover o acesso, a circulação e o uso de um número variado de atividades com textos. Os discursos e os valores constituídos localmente sobre demandas da leitura e da escrita vivenciadas por elas e os sentidos que atribuem a suas práticas geraram nelas um processo gradual de "empoderamento", apoiado em práticas de letramento.

As mulheres líderes das CEBs são agentes mobilizadoras de seus saberes e de suas experiências, ambos refletem em seus modos de fazer. Elas são promotoras e mediadoras das práticas cotidianas de uso da escrita para realizar as atividades visadas. Conhecem os meios, as limitações e as possibilidades, as fraquezas e as forças de cada um dos membros do grupo e de suas práticas locais. Conseguem, no convívio em comunidade, identificar pessoas que não são alfabetizadas, mas compreendem os papéis sociais da escrita e distinguem gêneros ou reconhecem as diferenças entre a língua escrita e a oralidade. Convivem também com pessoas alfabetizadas que, mesmo dominando o sistema da escrita, pouco vislumbram suas possibilidades de uso.

Essas mulheres percebem que não há um padrão para todos os indivíduos, para todos os tempos, pois, como afirmam Barton e Hamilton (1998), as práticas de letramento são culturalmente construídas. Sob essa perspectiva, tais práticas podem ser concebidas como um fenômeno mutável e dinâmico, visto que estão inseridas na sociedade, sendo passíveis de mudança.

Cada pessoa tem experiências e propósitos distintos para a leitura e a escrita. No caso desta pesquisa, observamos diferentes experiências das mulheres das CEBs e diversas demandas feitas a elas. Assim, notamos solicitações e objetivos diferentes, em relação ao ato de ler e escrever, para adultos e crianças, para homens e mulheres, e para as instituições sociais das quais participam.

Ao conhecer os modos de participação nas culturas do escrito de mulheres camponesas líderes das CEBs, podemos descrever as Comunidades Eclesiais de Base como um espaço de evento de letramento, circulação de textos e práticas de leitura e escrita. Já a família e a religião, o Movimento de Mulheres Camponesas, os sindicatos, o Movimento de Educação de Base e os programas de alfabetização de adultos são considerados como instâncias formativas; e a escola e a Igreja, como instâncias de difusão de textos e práticas de leitura e de escrita.

Concluímos, pois, que os modos de participação nas culturas do escrito são diversos e podem ser determinados pelas 
instituições, pelas políticas escolares e não escolares de alfabetização e pelos usos religiosos ou comerciais, típicos de um letramento situado na circulação. A escola não é a única guardiã da transmissão da escrita, embora sua forma escolar de lidar com a escrita possa atingir outros espaços sociais, mostrando que são múltiplas as relações entre espaços e sujeitos. A participação nos eventos e nas práticas de letramento está muito mais ligada a nossas experiências sociais e culturais do que ao próprio conhecimento do saber escolarizado.

\section{Referências}

Abreu, M. (Org.). (2002). Leitura, história e história da leitura. Campinas: Mercado de Letras.

Barton, D., \& Hamilton, M. (1998). Local literacies: reading and writing in one community. London: Routledge.

Bastos, L. C. (2011). Traçando metas, vencendo desafios: experiências escolares de mulheres egressas da EJA (Dissertação de Mestrado). Universidade Federal de Minas Gerais, Belo Horizonte.

Berning, C. (Diretor). (1994). Anel de tucum. Chácara Santo Antonio: Verbo Filme.

Betto, F. (1981). O que é Comunidade Eclesial de Base. São Paulo: Abril Cultural, Brasiliense.

Bucciol, A. (2004) Queremos ver Jesus e ser suas testemunhas. Livramento de
Nossa Senhora: Diocese de Livramento de Nossa Senhora.

Bucciol, A. (2007). Canta Povo de Deus. Livramento de Nossa Senhora: Diocese de Livramento de Nossa Senhora.

Castanheira, M. C., Crawford, T., Dixon, C. N., \& Green, J. (2001). Interactional ethnography: an approach to studying the social construction of literacy practices. Linguistics and Education, 11(4), 353-400.

Certeau, M. (1999). A invenção do cotidiano 1: artes de fazer. Petrópolis: Vozes.

Chartier, R. (2001). Do livro à leitura. In R. Chartier (Org.). Práticas da Leitura (pp. 77-106). São Paulo: Estação Liberdade.

Durkheim, E. (2002). As regras do método sociológico. São Paulo: Martin Claret.

Feitosa, D. A. (2005). Cuidado $e$ sustentação da vida: a interface $d a$ educação popular no cotidiano de mulheres recicladoras (Tese de Doutorado). Universidade Federal do Rio Grande do Sul, Porto Alegre.

Flick, U. (2004). Uma introdução à pesquisa qualitativa. Porto Alegre: Bookman.

Fonseca, M. C. F. R. (2005). Educação matemática de jovens e adultos: especificidades, desafios e contribuições. Belo Horizonte: Autêntica.

Galvão, A. M. O. (2001). Cordel: leitores e ouvintes. Belo Horizonte: Autêntica.

Galvão, A. M. O. (2004). Leitura: algo que se transmite entre gerações? In V. Ribeiro (Org.). Letramento no Brasil: reflexões a partir do INAF 2001 (pp. 125-153). Campinas: Global. 
Galvão, A. M. O. (2010). História das culturas do escrito: tendência e possibilidades de pesquisa. In Marinho, M., \& Carvalho, G. T. (Orgs.). Cultura escrita e letramento (pp. 218-278). Belo Horizonte: Ed. UFMG.

Galvão, A. M. O., \& Di Pierro, M. C. (2007). Preconceito contra o analfabeto. São Paulo: Cortez Editora.

Green, J., Dixon, C., \& Zaharlick, A. (2005). A etnografia como uma lógica de investigação. Educação em Revista, 42, 13-79.

Instituto Brasileiro de Geografia E Estatística. (2011). Censo Demográfico 2010. Recuperado de: http://www.ibge.gov.br/home/estatistica/po pulacao/censo2010/caracteristicas_da_pop ulacao/resultados_do_universo.pdf

Kleiman, A. B. (2008). Modelos de letramento e as práticas de alfabetização na escola. In Kleiman, A. B. (Org.). Os significados do letramento: uma nova perspectiva sobre a prática social (pp. 1561). Campinas: Mercado de Letras.

Marinho, M. (2010). Letramento: A criação de um neologismo e a construção de um conceito. In Marinho, M., \& Carvalho, G. T (Orgs.). Cultura escrita e letramento (pp. 68-100). Belo Horizonte: Editora UFMG.

Nogueira, V. L. (2003). Educação de Jovens e Adultos e gênero: um diálogo imprescindível à elaboração de políticas educacionais destinadas às mulheres das camadas populares. In Soares, L. (Org.). Aprendendo com a diferença: estudos $e$ pesquisas em Educação de Jovens $e$ Adultos (pp. 65-90). Belo Horizonte: Autêntica.

Oliveira, M. K. (2009). Cultura $e$ psicologia: questões sobre o desenvolvimento do adulto. São Paulo: Hucitec.

Paz Albuquerque, K. (2007). Mulheres pobres na Diocese de Goiás - uma trajetória de participação e emancipação feminina (Dissertação de Mestrado). Pontifícia Universidade Católica de Goiás, Goiânia.

Reis, S. M. A. O. (2009). A inserção dos egressos da educação popular na escola pública: tensão entre regulação $e$ emancipação (Dissertação de Mestrado). Universidade Federal de Minas Gerais, Belo Horizonte.

Rojo, R. (2009). Letramentos múltiplos, escola e inclusão social. São Paulo: Parábola Editorial.

Rojo, R., \& Moura, E. (2012). Multiletramentos na escola. São Paulo: Parábola.

Silva, S. B. A., \& Galvão, A. M. O. (2007). Práticas religiosas pentecostais e processos de inserção na cultura escrita (Pernambuco, 1950-1970). In Galvão, A. M. O., Melo, J. F., Souza, M. J. F., \& Resende, P. C. (Orgs.). História da cultura escrita: séculos XIX e XX (pp. 365-403). Belo Horizonte: Autêntica.

Souza, M. J. F. (2007). Uma aprendizagem sem folheto: quem ainda vai rezar e benzer em Barra do Bengoso? In Galvão, A. M. O., Melo, J. F., Souza, M. J. F., \& Resende, P. C. (Orgs.). História da cultura escrita: séculos XIX e XX (pp. 405-435). São Paulo: Autêntica.

Souza, M. J. F. (2009). Modos de participação nas culturas do escrito em uma comunidade rural no Norte de Minas Gerais (Tese de Doutorado). Universidade Federal de Minas Gerais, Belo Horizonte. 
Street, B. (1984). Literacy in theory and practice. Cambridge: Cambridge University Press.

Vóvio, C. L., \& Kleiman, A. B. (2013). Letramento e Alfabetização de Pessoas Jovens e Adultas: um balanço da produção científica. Cad. Cedes, 33(90), 177-196. Recuperado de: http://www.scielo.br/pdf/ccedes/v33n90/a0 2v33n90.pdf

i Inicio este relato usando a primeira pessoa do singular (eu), pois este trecho está relacionado a uma vivência pessoal com o objeto de pesquisa.

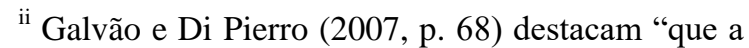
convivência com leitores na infância, a disponibilidade de materiais de leitura, o hábito de frequentar bibliotecas, a variedade de leituras e de fontes de informação sobre temas da atualidade influenciam no letramento da população". Ler e escrever envolve todo o meio social do sujeito.

iii Sobre a ampliação e a circulação de impressos católicos e espaços/situações de usos desse material, ver estudo realizado por Souza (2009) em uma comunidade rural do Norte de Minas Gerais.

${ }^{\text {iv }}$ As CEBs são ligadas à Igreja Católica, as quais, incentivadas pelo Concílio Vaticano II (19621965), espalharam-se, principalmente, entre 1970 e 1980 pela América Latina. Reúnem-se, geralmente em função da proximidade territorial, e são compostas, sobretudo, por membros das classes populares (Betto, 1981).

A Diocese de Caetité/BA, localizada na microrregião da Serra Geral, foi criada em 20 de outubro de 1913. Possui uma área de $41.979,6 \mathrm{~km}^{2}$, um total de 35 municípios e 33 paróquias, divididas em 9 zonais pastorais. A população da microrregião citada está estimada em 674.346 habitantes, dos quais $90 \%$ se consideram católicos (IBGE 2010).

${ }^{\text {vi }}$ Para preservar a identidade das mulheres, foram utilizados nomes fictícios, indicados por elas.

vii Candiba é um município da Região da Serra Geral e da mesorregião da Região Centro-Sul da Bahia. Tem 13.210 habitantes (IBGE, 2010). Na área urbana, residem 7.725 pessoas; e, na rural, 5.485 pessoas. Há 6.815 homens e 6.395 mulheres.
Em relação ao Brasil, esse município inverte a proporção usual dos gêneros.

viii Tática, no sentido proposto por Michel de Certeau (1999, p.94-95), “é a prática cotidiana daquele que não tem poder ... É a astúcia de se fazer algo diferente do que estava estabelecido, do que é dado como pronto".

ix O Movimento de Educação de Base de Iniciativa Católica é um de projeto de Alfabetização de Jovens e Adultos que atende pessoas a partir dos 15 anos de idade ainda não alfabetizadas. Funciona nos salões comunitários da Paróquia de Santo Antônio, alocada no município de Guanambi/BA. Para saber mais, ver estudo de Reis (2009).

$x$ Os textos multimodais ampliaram as possibilidades de leitura, pois podem definir o ponto de partida e de limite da leitura, a ordem em que se vai ler, a conexão entre os textos. Além de buscar variação de linguagens, devem criar relações coerentes entre elas. Para saber mais, veja os textos de Rojo (2009; 2012).

Informações do artigo / Article Information

Recebido em : 31/05/2018

Aprovado em: 26/06/2018

Publicado em: 23/12/2018

Received on May 31th, 2018

Accepted on June 26th, 2018

Published on December 23th, 2018

Contribuições no artigo: As autoras foram responsáveis pela elaboração, análise e interpretação dos dados; escrita e revisão do conteúdo do artigo, e aprovação da versão final publicada.

Author Contributions: The authors were responsible for the designing, delineating, analyzing and interpreting the data, production of the manuscript, critical revision of the content and approval of the final version published.

Conflitos de interesse: As autoras declararam não haver nenhum conflito de interesse referente a este artigo.

Conflict of Interest: None reported.

Orcid

Sônia Maria Alves de Oliveira Reis http://orcid.org/0000-0003-0129-0719

Carmem Lúcia Eiterer

http://orcid.org/0000-0002-6978-155X 
Reis, S. M. A. O., \& Eiterer, C. L. (2018). Práticas de leitura e escrita de mulheres camponesas: reflexões a partir de algumas histórias de apropriação...

\section{Como citar este artigo / How to cite this article}

APA

Reis, S. M. A. O., \& Eiterer, C. L. (2018). Práticas de leitura e escrita de mulheres camponesas: reflexões a partir de algumas histórias de apropriação. Rev. Bras. Educ. Camp., 3(4), 1316-1344. DOI: http://dx.doi.org/10.20873/uft.2525-4863.2018v3n4p1316

ABNT

REIS, S. M. A. O.; EITERER, C. L. Práticas de leitura e escrita de mulheres camponesas: reflexões a partir de algumas histórias de apropriação. Rev. Bras. Educ. Camp., Tocantinópolis, v. 3, n. 4, set./dez., p. 1316-1344, 2018. DOI: http://dx.doi.org/10.20873/uft.2525$\underline{4863.2018 v 3 n 4 p 1316}$ 